\title{
Life and Performance Tests of O F Lightning Arresters
}

\author{
BY N. A. LOUGEE \\ of the General Electric Co.
}

\section{I-LIFE RUN TESTS OF $O F$ ARRESTERS}

CINCE the first papers on the oxide film $(O F)$ lightning arrester were given a little over two years ago, ${ }^{1}$ the arrester has proved itself to be a worthy piece of apparatus by performance in regular

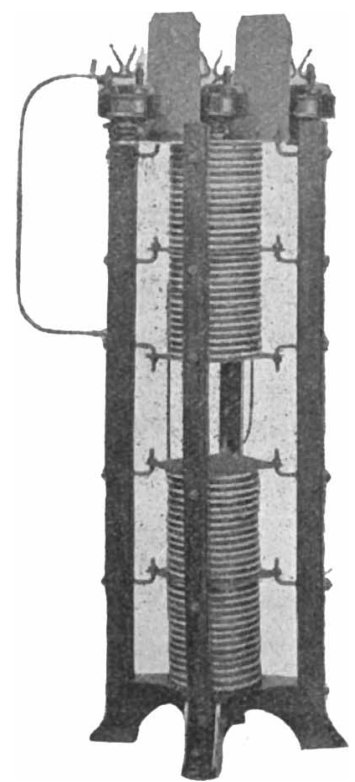

Fig. 1-Oxide Film Lightning Arrester for Indoor Service on Three-Phase Circuits, 5000-7500 Volts

service. Several hundred arresters up to $73-\mathrm{kv}$. rating, are now installed on both indoor and outdoor

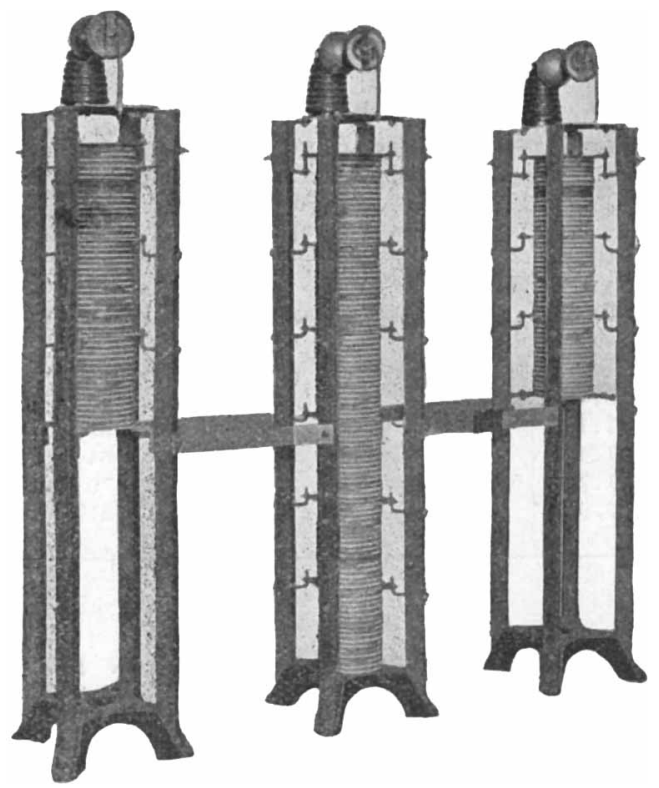

Fig. 2-Oxide Film Lightning Arrester for Indoor Service on Three-Phase Circuits, 15000-25,000 Volts

circuits, and higher voltage units will soon be in service. Figs. 1, 2, 3 and 4 show the typical designs used.

1. The $O F$ Lightning Arrester, Trans., A. I. E. E., Vol. XXXVII, 1918.

To be presented at the Chicago Meeting of the A.I.E.E., November 12, 1920.
In Fig. 1, the three phase legs and the ground leg are all arranged in one stack, the bottom section being the ground leg. In Fig. 2, the three phase legs are the

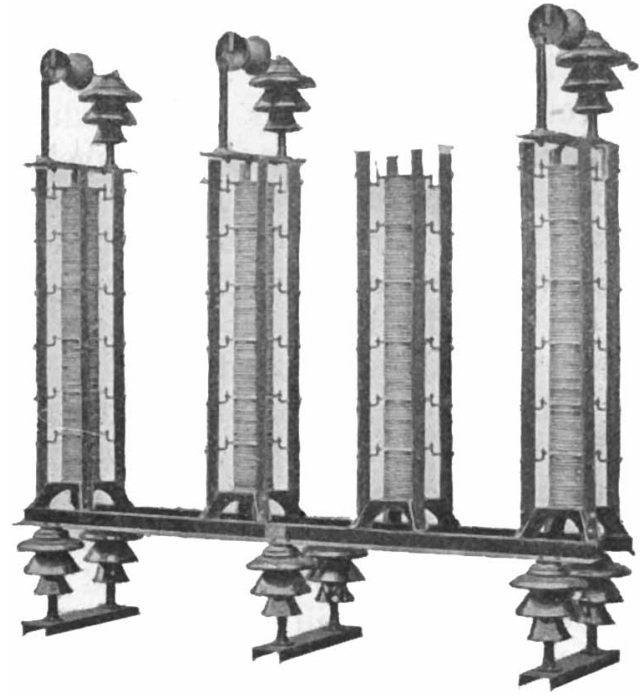

Fig. 3-Oxide Film Lightning Arrester for Indoor Service on Three-Phase Circuits, 37,000-50,000 Volts

upper sections and the ground leg is the lower section. In Figs. 3 and 4 , the three phase legs and ground leg are set up parallel to one another. Fig. 5 shows the covered sphere gap. used with the outdoor design, which permits of an indoor setting. Due to the small leakage current of these arresters (about 0.010 ampere),

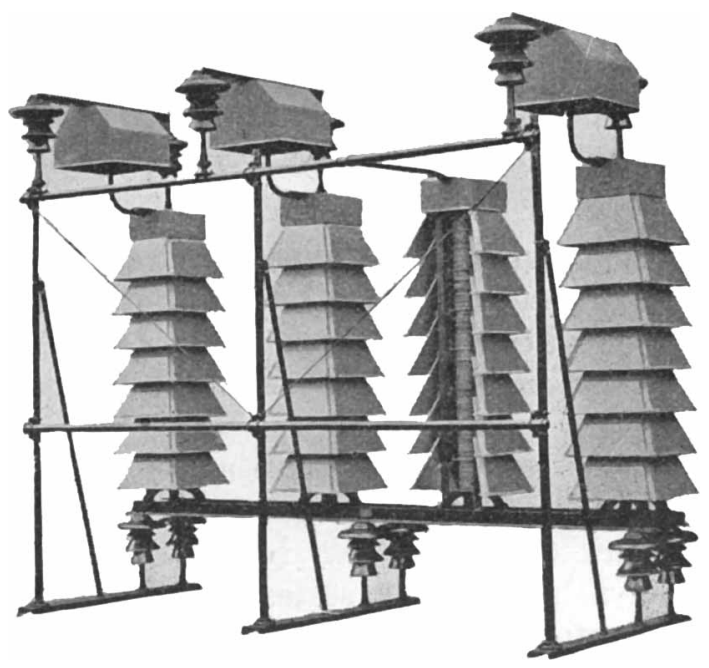

Fig. 4-Oxide Film Lightning Arrester for Odtdoor Service on Three-Phase Circuits, 50,000-73,000 Volts.Grodnd Stack Shields Removed for Cell Inspection and TEST

it is not necessary to use horn gaps to aid in breaking the arc, and it is, therefore, possible to use the covered sphere gap which has previously been described in the proceedings of the Institute. ${ }^{2}$ Fig. 6 shows the

2. The Effect of Transient Voltages on Dielectrics-II, F. W. Peek, Jr., Trans., A. I. E. E., Vol. XXXVIII. 
testing device used and its method of operation, about which more will be said a little later.

The life of a lightning arrester is a very important factor, and one that has to be estimated from both operating and laboratory data. Operating data obtained during the past five years show that little deterioration has occurred to the $O F$ cells. Cells have been returned from typical installations and tested and little, if any, change has been found.

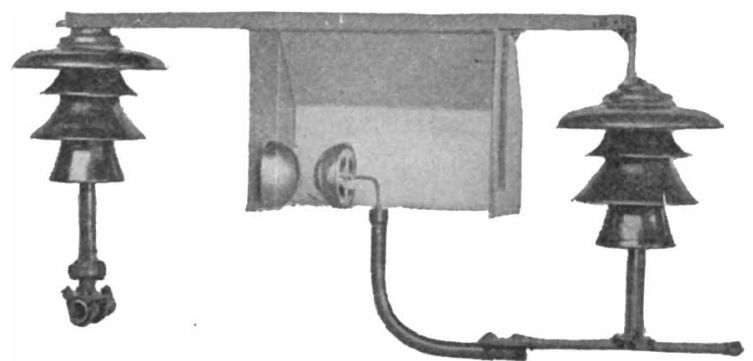

Fig. 5-Covered Hemisphere Gap as Used on Odtdoor Type Oxide Film Arrester-50,000-73,000 Volts-Section of Cover Omitted to Show Gap

Fig. 7 is a view of an opened returned cell, and shows the film side of the electrodes and the porcelain spacer. The lead peroxide $\left(\mathrm{P}^{\mathrm{b}} \mathrm{O}_{2}\right)$ filler has been removed. This cell was returned recently from a 13,000 -volt arrester installed early in 1916, and which has been subjected to much more than average service, due to its location and surroundings. The few white spots in the illustration are discharge areas covered with yellow litharge $(P b O)$. This $P b O$ area or plug is what has caused the cell to reseal after the surge has passed through, and is reduced from the $\mathrm{PbO}_{2}$ filler by the heat of the current through the small discharge spot in the film. The larger dark areas are where some

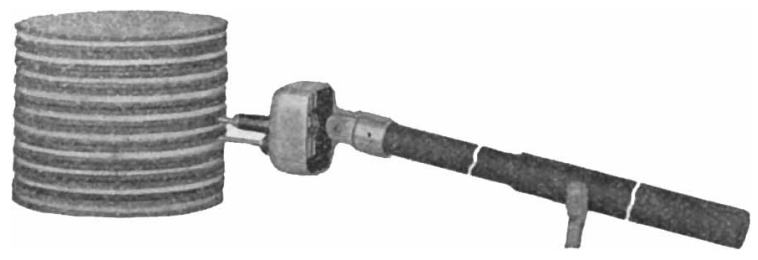

Fia. 6-Oxide Film Cell Testing Device in Position for Testing

of the $\mathrm{PbO}_{2}$ filler is still adhering to other discharge areas, and the light background is the varnish film. The lead peroxide filler showed no change.

To obtain information on the life of $O F$ arresters several years ahead of outside reports, however, an intensive test has been running during the past. few years. Fig. 8 gives the general scheme of circuit used.

In Fig. 8 , the surge circuit is shown to the right and consists of the usual inductance, capacitance and air gap, used to obtain oscillations. The 50,000volt transformer charges the condensers, which, upon breaking down the air gap set for a little under 50,000 volts, cause the surge through the arresters.
The transformer to the left supplies the dynamic 60-cycle voltage to all the arresters running on this particular voltage. Ordinarily all the lever switches are down (Fig. 8 shows only one particular voltage, one arrester and one set of switches. With this arrangement the arresters are separate from the

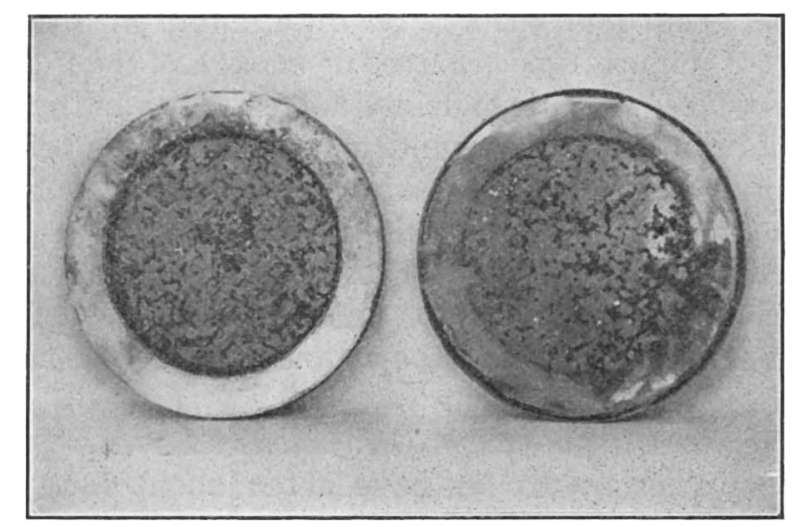

Fig. 7-Inside of Electrodes of $O F$ Lightning Arrester Cell Returned From 13,000-Volt Installation After Four Years of Service

surge circuit. When it is desired to surge any one particular arrester, the upper lever switch corresponding to this arrester is thrown, thus paralleling the two transformers supplying dynamic voltage. The lower lever switch is then opened and this particular arrester is still on dynamic voltage, but also on the surge circuit which can now be thrown on. After surging, this arrester is thrown back on the regular dynamic transformer, and the next arrester put through a similar operation. This

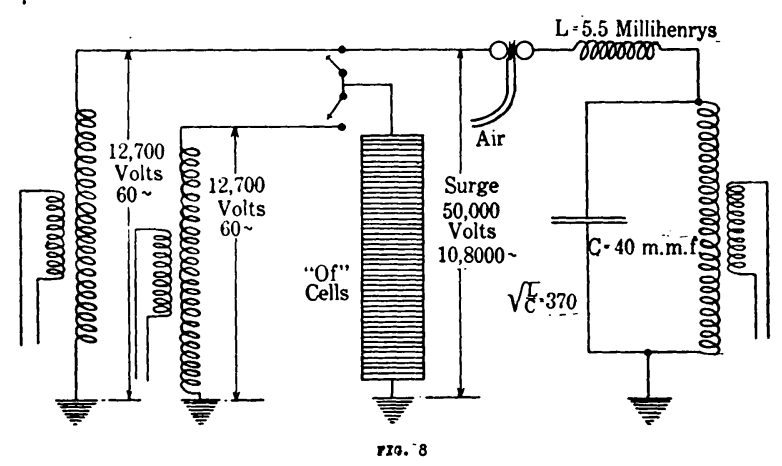

Fig. 8-Circuit Connection Used in Intensive Life Run Tests

arrangement of transformers and switches permits the regular dynamic voltage to all the arrester to be uninterrupted during surging operations.

$O F$ arresters were placed on 330,2300 and 12,700 volts respectively at 60 cycles with no series gap, and all arranged as shown in Fig. 8. These arresters have been surged daily, the surge current through the arresters having a maximum peak value of about $50 \mathrm{am}-$ peres and dying down to about 20 amperes at the end. This surge, having a surge impedance of $370 \mathrm{ohms}$ is representative of an actual surge on a line, except that 
the average actual surge has a higher frequency and may at times be more powerful. It has been found, however, that the lower the frequency of a surge, the more difficult it is for an arrester to seal. 330-Volt Circuit-Single O F Cells.

These cells take from 5 to 75 milliamperes leakage current and run at a temperature of about $50 \mathrm{deg}$. cent. It took about four years to record a failure with these cells. A failure then occurred by enough of the $\mathrm{PbO} \mathrm{O}_{2}$ being reduced to cause high internal resistance and hence loss of protection. The voltage across the cells being, of course, always the same, causes this group of cells to be more permanent than the 2300- and 12,700-volt arresters. With these latter arresters the voltage distribution across the various cells may change. This adds one more variable to the action of arresters consisting of more than one cell.

2300-Volt Circuit-Eight O F Cells in Series.

These arresters so far have acted about like the single cells; that is, voltage distribution has remained normal. Voltage distribution is obtained by means of shunting vacuum tubes, which break down or glow at various voltages, across each cell in turn. It is the same idea used to test the cells in service as shown in Fig. 6. For service conditions a vacuum tube which will glow at about 1000 volts a-c. is used. As the internal condition of a cell changes, and more particularly the film, the voltage drop when in series with a number of cells may change. Although this is not an infallible method of picking out poor cells in service, it does give a reliable indication in most cases. For voltage distribution tests, tubes breaking down between 100 and 2300 volts a-c. respectively are used. For conveniencein interpolating these data, a cell having a voltage drop of less than 200 is designated low, from 200 to 400 is designated normal, from 400 to 600 is designated high, and above 600 is designated very high. The results can then be plotted against the respective cells by using a different color for each of the above four groups. The units on 2300 volts have shown with one or two exceptions only normal cells on voltage distribution, and the few low or high cells which have appeared from time to time, have returned again to normal. The leakage current of this group of arresters varies between 1 and 10 milliamperes, and the cells run at a temperature of about 40 deg. cent. A few units have failed or lost their protection after four years of continuous service.

12,700-Volt Circuit-Forty-seven O F Cells in Series.

These arresters have been running almost two years with no appreciable deterioration. To obtain the relative effect of dynamic and surge, similar arresters were run with different service characteristics, as follows: (a) dynamic only, (b) dynamic and surge, (c) surge only and (d) idle. The leakage current is from 5 to 10 milliamperes and about the same through all the arresters. The temperature is about $35 \mathrm{deg}$. cent. at the top of the stack, $45 \mathrm{deg}$. cent. in the middle and $30 \mathrm{deg}$. cent. at the bottom of the stack. Results to date show that (a) and (b) types of arresters give about the same characteristics; that is, the daily surge has no ill effect on the arresters. Both (a) and (b) show a gradual tendency for low-voltage cells to appear at the bottom of the stack and higher voltage cells at the top. Here again no change has been found to be absolute; that is, unless a cell is extremely high, it may go from low to high and back again. The low cells at the bottom of a stack may be due to either capacity or temperature, but probably the latter, as all the cells are about normal when first put on the circuit. The (c) and (d) types of cells show a general scattering of high and low cells throughout the stack.

This sort of intensive test has been found extremely valuable in trying to determine ahead of time what might occur in service and also for determining the effect of changes. So far as applying to standard arresters in service, it seems fair to assume that if an arrester will stand, say four years, under such an intensive test, it will stand up several times four years in actual service. Of course, it is always possible that a more or less direct lightning stroke or a long arcing ground will destroy an arrester, so this conclusion should apply to normal average service. As yet the factor to use between test and actual service is not known, but should be when longer service results are available.

\section{II - PERFORMANCE OF $O F$ ARRESTERS}

The efficiency of a lightning arrester is governed by four factors; namely, sensitiveness, current discharge capacity, reseal and life.

Sensitiveness. As most electrical apparatus is tested at twice normal voltage, an arrester should be able to begin discharging at about this voltage. This means a horn or sphere gap should not be set for over double voltage for best results.

To care for steep wave impulses the time lag of the arrester should be a minimum.

Current Discharge Capacity. To discharge the energy from a surge, the discharge path must be of a sufficiently low resistance to prevent the voltage drop being above the insulation strength of the apparatus connected to the line. Again since a double voltage test is given apparatus, the discharge capacity of an arrester is usually given at double rated voltage.

Reseal. Reseal is the act of cutting off the discharge path through the arrester when the voltage across the arrester has returned to normal. The quicker this can be accomplished the better it will be, for if an arrester has sufficient discharge capacity, dynamic or line frequency current following, not only will be apt to destroy the arrester but may also cause bad disturbances on the line.

Reseal should also permit an arrester to be ready immediately for another discharge, for with a lightning storm over a large area of transmission lines, it is fair to assume that impulses and surges can occur extremely 
close together; that is, at least a second apart, and sometimes several per second.

Life. It is difficult to define exactly what the life of a satisfactory arrester should be, but a good arrester

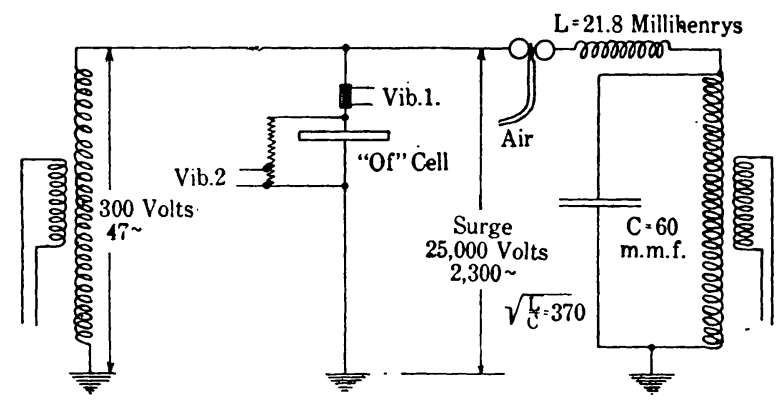

Fig. 9-Circuit Connection Used for Surge Tests

should easily withstand the average surge or impulse. Arcing grounds are the most dangerous type of discharges and as they vary greatly in severity, depending upon the system and just where they occur, it is diff-

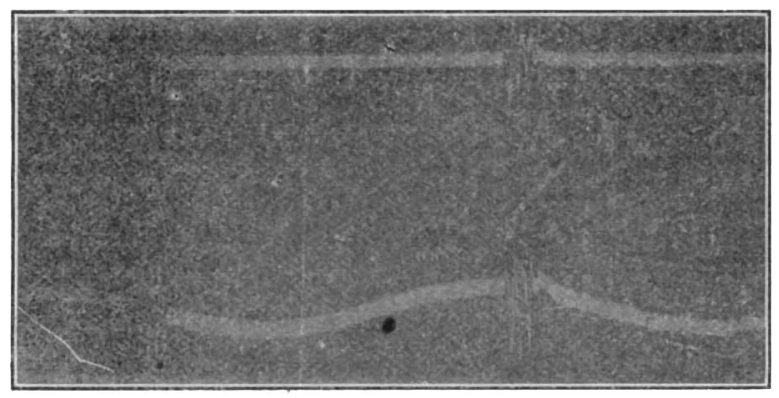

Fig. 10-O F Cell on Circuit in Fig. 9 Vibrator 1-Current through arrester, $1 \mathrm{~mm} .=5$ amperes (peak value) Vibrator 2-Voltage across arrester, $1 \mathrm{~mm}$. $=85$ volts (peak value)

cult to state how long an arrester should care for one.

Tests. The following results are given to show how the $O F$ arrester acts in regard to the above points. A single cell was used in all the following tests in order to

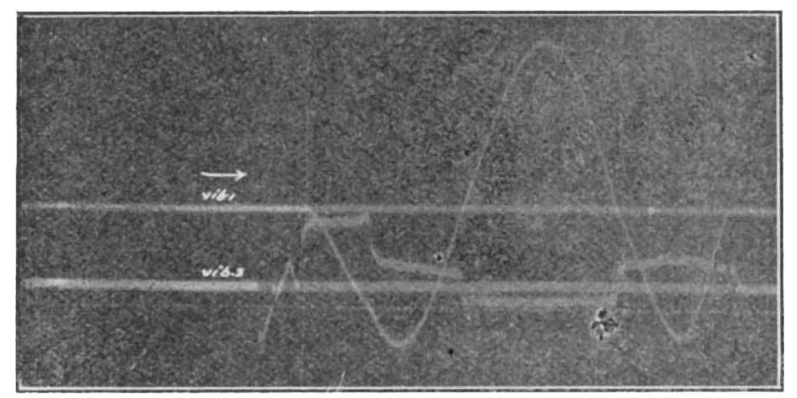

Fig. 11-O F Cell on a 600-Volt, 40-Cycle Circuit Vibrator $1-$ Current through arrester, $1 \mathrm{~mm}$. $=100$ amperes. Vibrator 2-Voltage across arrester, $1 \mathrm{~mm}$. $=22$ volts.

obtain as powerful discharges through the cell as possible with the power available.

The first set of tests was made with a circuit as shown in Fig. 9. The usual surge circuit is used, which superimposes the 25,000-volt, 2300-cycle surge on the dynamic 300-volt, 47-cycle circuit. Fig. 10 shows an oscillogram of the discharge of an $O F$ cell on this circuit. Vibrator 2 shows the dynamic 47-cycle voltage across the arrester with the 25,000-volt, 2300-cycle surge superimposed. The voltage peaks are kept at about double voltage and the cell reseals without permitting any dynamic current to follow; that is, this test shows that reseal and sensitiveness are satisfactory.

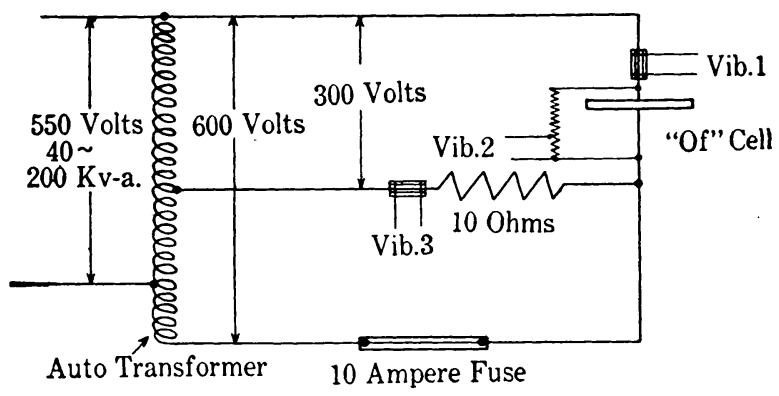

Fig. 12-Circuit Connection Used for Double-Voltage Surge Tests

Although the discharge through the cell is about $50 \mathrm{am}$ peres, since the surge is supplied by a $15-\mathrm{kv}-\mathrm{a}$. transformer, this test is not enough in itself to demonstrate that the discharge capacity is satisfactory.

Fig. 11 shows an oscillogram taken with 600 volts, 40 cycles (double standard voltage) impressed across an $O F$ cell, to show current discharge capacity. The current peaks are 3500,4200 and 3300 amperes respectively, and the voltage peaks 110,89 and 154 volts respectively, giving an internal resistance of $0.031,0.021$ and $0.047 \mathrm{ohm}$ respectively. Due to the low resistance of the $O F$ cell and its relative value to the im-

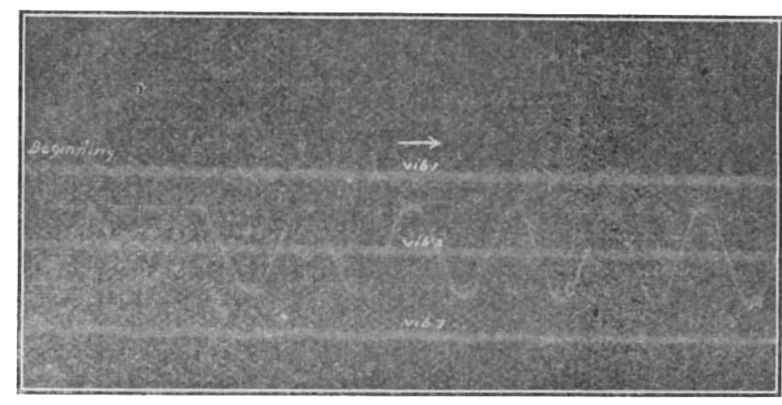

Fig. 13-O F Cell on Circuit in Fig. 12

Vibrator $1-$ Current through arrester at 600 volts, $1 \mathrm{~mm}$. $=100$ amperes Vibrator 2-Voltage across arrester, $1 \mathrm{~mm}$. $=22$ volts.

Vibrator 3-Current through arrester at 300 volts, $1 \mathrm{~mm} .=5$ amperes.

pedance of the circuit, the impressed voltage of 600 was not sustained across the cell when the high current flowed. This current discharge capacity is extremely high and should be ample under all conditions. The internal resistance of a cell will vary between 0.01 and $0.1 \mathrm{ohm}$, depending upon the particular path through the cell the discharge happens to pick out.

Fig. 12 gives the connection used for a double voltage surge test with normal voltage immediately following. This is accomplished as shown by bringing out a tap from the transformer at 300 volts (standard volt- 
age) and connecting it through a low resistance to the arrester cell. The resistance is necessary to prevent the lower section of the transformer from becoming short-circuited. With this connection, 600 volts are supplied to the arrester until the fuse opens, and the lower half of the transformer then being cut off, 300

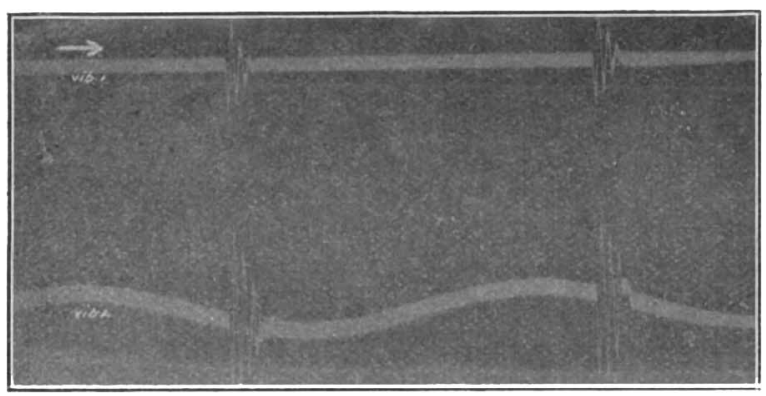

Fig. 14- $X$ Arrester on Circuit in Fig. 9 Vibrator 1 -Current through arrester, $1 \mathrm{~mm}$. $=5$ amperes (peak value) Vibrator 2-Voltage across arrester, $1 \mathrm{~mm}$. = 85 volts (peak value).

volts are continued across the arrester cell. This is about the most severe test that can be given a lightning arrester and only an arrester which has a lowbreakdown, good current discharge capacity and good sealing characteristics, will act satisfactorily. Referring to the oscillogram taken on this circuit shown in Fig. 13, the switch impressing 600 volts across the cell closed at the extreme right. The cell immediately broke down and discharged 2700 amperes. This current after one-half cycle blew the 10-ampere fuse, thereby cutting off onehalf of the transformer, and causing the voltage across the cell to drop to 300 or normal. There was then a sealing current of about 2 amperes for several cycles shown by vibrator 3 , which caused the small breaks in the voltage wave. After a few seconds the current through the cell had dropped to normal or a few milliamperes.

To show the relation of protection and current discharge capacity, oscillograms were taken of single $O F$ cells with external resistance in series on the ciruit shown in Fig. 9. $X$ represents an arrester with a medium internal resistance and having a discharge capacity at double voltage of 60 amperes. $Y$ represents an arrester with a higher internal resistance and having a discharge capacity of 20 amperes at double voltage.
Fig. 14 shows an oscillogram taken with arrester $X$ and Fig. 15 an oscillogram taken with arrester $Y$ on this circuit. It will be noted that the voltage peaks with $X$ are 1600 and with $Y 3650$, as against 900 with the . standard cell, which was shown in Fig. 10. Moreover if the frequency were nearer what is obtained in actual service, that is, from 10,000 to 100,000 cycles instead of 2300 cycles which had to be used for oscillographic work, this difference would have been much greater due to the higher impedance of the transformer at the higher frequencies. To give, therefore, satisfactory protection, an arrester must have a good current discharge capacity on double voltage and more than these $X$ and $Y$ arresters show. $X$ and $Y$ also show the bad effect of a poor ground connection.

The life of an $O F$ arrester was discussed in Part I, Life Run Tests on $O F$ Arresters, and is believed to be satisfactory.

Sensitiveness in service is limited by the gap setting, but since no dynamic current follows a surge discharge and the leakage current is only a few milliamperes, this gap setting can be small. The gap settings used in service correspond to line voltage, so the breakdown be-

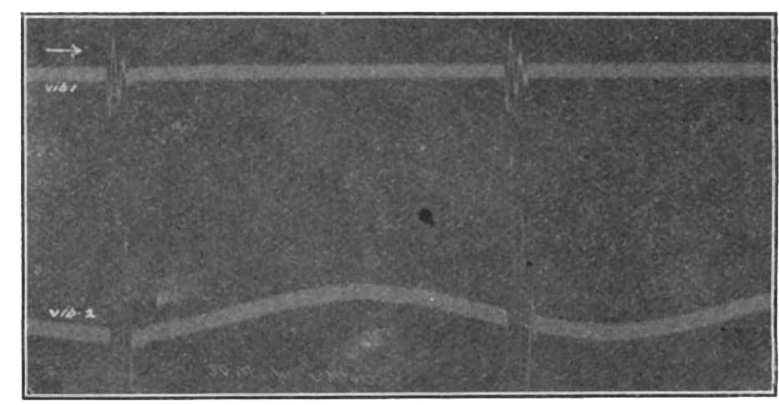

Fig. 15-Y Arrester on Circuit in Fig. 9

Vibrator 1-Current through arrester, $1 \mathrm{~mm} .=5$ amperes (peak value). Vibrator 2-Voltage across arrester, $1 \mathrm{~mm}$. $=85$ volts (peak value).

tween phases is double voltage and the breakdown to ground is 1.7 times the voltage to ground. Since the covered gap is used for outdoor installations a dry or indoor setting can be used.

The author wishes to express his appreciation to Mr. E. E. Burger for his valuable assistance in obtaining the data used in this paper.

\section{INVESTIGATIONS IN THE AUTOMOTIVE FIELD}

Sometime ago, the Bureau of Standards commenced an investigation of the value of various systems of pre-heating the air-fuel mixtures used in automobile engines. A paper on this subject was presented at the June meeting of the Society of Automotive Engineers. Work has been continued and more complete data secured concerning the effect of different degrees of heating on engine economy, acceleration, etc. Several special fuels to be used in the airplane engine tests carried out in cooperation with McCook
Field, have been analyzed as well as some blended fuels submitted for investigation by the Inventions Section of the War Department. Apparatus has been set up and test commenced to determine the performance of fan belts for the Motor Transport Corps. The apparatus consists of a motor driving a typical automobile cooling fan by means of a belt; the slippage can be determined by means of revolution counters attached to the motor and the fan pulley. 